seldom the outcome of the stammering mind of Mr. Ready-tohalt. The armed neutrality which promises operation if the need arises was, and is, the orthodox plan and has much to say for itself; but as Carlyle remarks, "The two internecine plans collapsing into one, that is the clearly fatal method." The great majority, if not all, of the chronic cases have commenced as an acute disease and it is an imporant practical question, how long may they be regarded as remaining so? That is, after what interval should the complete operation and not the so-called operation for acute disease be performed? Many cases in which the operation for acute disease has been performed subsequently require the complete operation and I am now of opinion that in any case requiring operation after six weeks discharge the surer treatment is the complete opera-

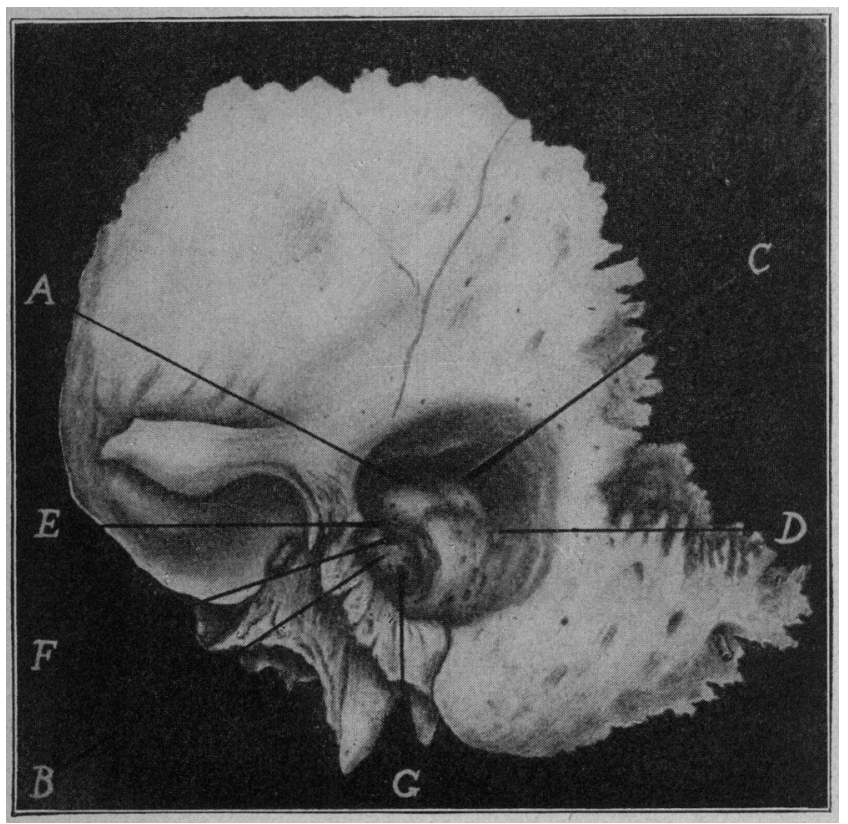

Fig. 40.- Showing the completed mastold operation and the cavities for packing. A, gutter-like concavity connecting the attic and antrum, representing the partially obliterated aditus ad sntrum; $B$, promontory ; C, antrum space ; $D$, mastold space; $E$, location of the facial nerve; $F$, fenestra ovalis; $G$, fenestra rotundum.

tion. The operation for acute disease is an incomplete procedure and therefore uncertain in its results; the bridge is not divided, the abscess is incised only at its two extremities, the narrow neck of the antrum provides only imperfect drainage, and is liable to become blocked by granulations. In cases of ingravescent appendicitis no surgeon would dare to call himself a late operator, but no one who has attended meetings at which the treatment of temporal bone disease has been debated can fail to be struck with the fact that the orators seem to plume themselves on avoiding operation. Is this a logical

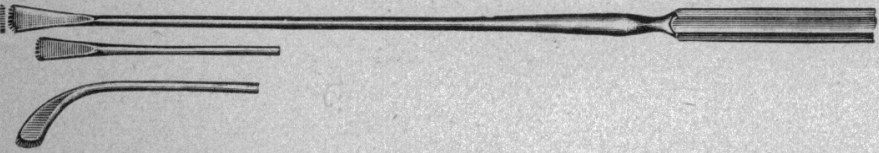

Fig. 41.-Showing the narrow edged packer; different sizes and shapes.

position to take up in treating a disease which is also ingravescent and which has perhaps a history of twenty years' standing, which may be tuberculous, and which in any case is liable to infect other parts of the body? The best results both to the hearing and to the heaIth of the patient in suppurative temporal bone disease are obtained by early and complete operation. No surgeon would leave a sinus leading to diseased bone in the tibia for twenty years, or even for one, however cleverly he might be able to irrigate it or tickle it with antiseptic. powders and cotton-wool. In mastoid disease, as in Bunyan's allegory, the Messrs. "Hopeful," who are persuaded to stray along the easiest going of By-path Meadow, will not escape the crab-tree cudgel in the dungeons of Giant Despair." 72 Madison Street.

\section{PULSUS PARADOXUS IN PERICARDITIS WITH EFFUSION.}

\section{W. J. CALVERT, M.D.} COLUMBIA, MO.

Pulsus paradoxus is one in which, during inspiration, the pulse becomes feeble or imperceptible. Since the time of Griesenger and Kussmaul pulsus paradoxus has been observed in a variety of pathologic conditions. F. Rigel $^{1}$ classifies these conditions as follows:

1. Mechanical interference with the large veins and aorta, as in Kussmaul's case. Here the heart is unaffected.

2. Obstructions in the air passage, causing an increased negative intra-thoracic pressure, which inhibits the heart's action.

3. Lowered activity of the heart.

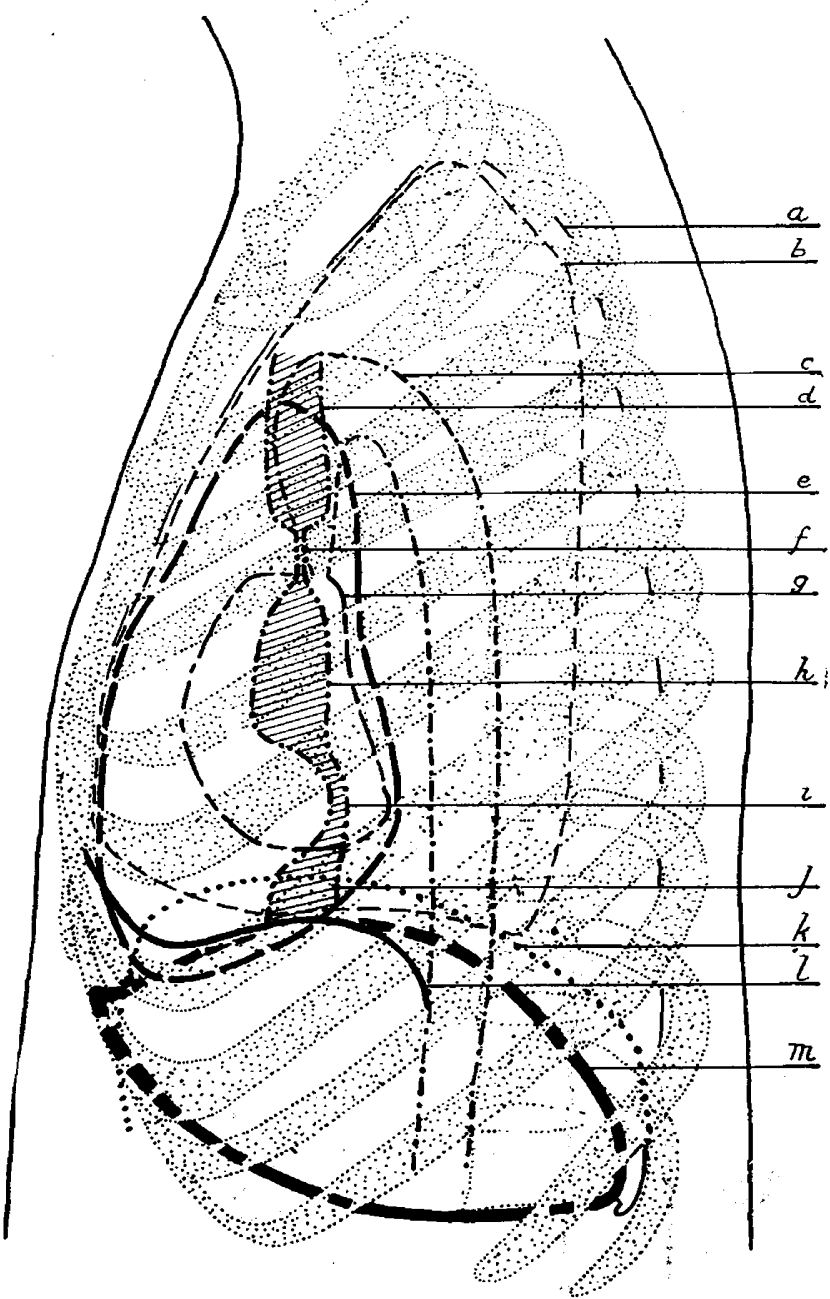

Fig. 1.-View of organs from left side. a, Parietal pleura; b, left lung; $c$, aorta ; $d$, superior vena cava; $e$, pericardium; $f$, col lapsed superior cava; $g$, heart; the heart is curved as shown :.. Figure 2, so that this projection is much thicker than the heart really is; $h$, right auricle; 1 , collapsed inferior cava; $j$, inferior vena cava; $k$, right cupola of diaphragm; 1 , central tendon of diaphragm; $m$, left cupola of diaphragm.

Pulsus paradoxus is a distinct variation from the normal, consequently it is pathologic and must have a cause. As pulsus paradoxus has been observed in a variety of conditions, its causes must vary, but in each condition this cause should be constant. From a clinical point of view pulsus paradoxus should be a sign of the existence of its cause, and the importance of this sign must depend

1. Deutsch. med. Wochschr. xix, $1903,345$. 
- on the nature of the pathologic condition. From a diagnostic point of view pulsus paradoxus is not of especial differential importance, but as it does not exist throughout the entire course of a given clinical picture, pulsus paradoxus heralds the development of a stage in the clinical course of a disease.

Recently I have had an opportunity to study the cadavers of two individuals who had pericardial effusion at the time of death, and in this paper I shall attempt to show the physical explanation of pulsus paradoxus and its significance in cases of pericarditis with effusion. The material for this paper was obtained from Dr. C. M. Jackson, to whom I wish to express my thanks.

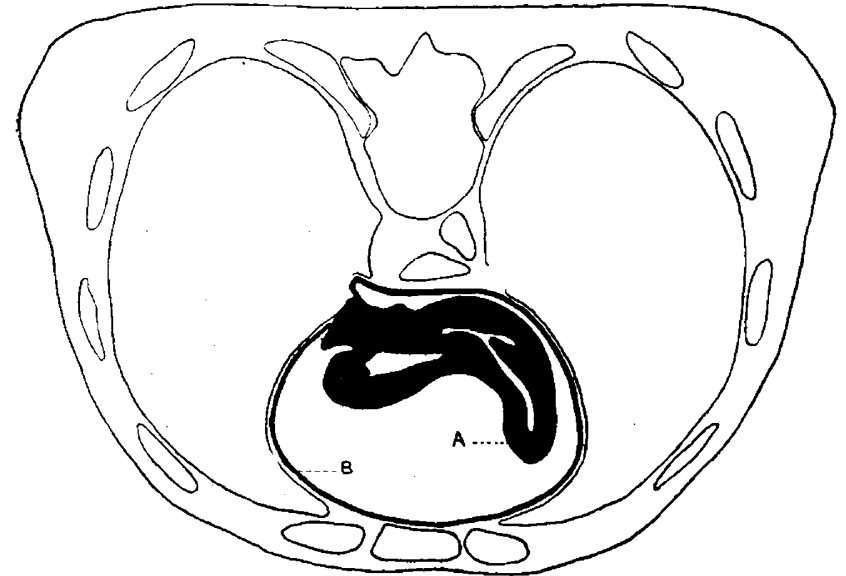

Fig. 2.-Transverse section of body showing flattened condition of the heart (A) and Its relation to the pericardial wall (B).

The cadavers were injected with formalin and allowed to harden, after which they were transversely sectioned. Drawings and measurements of the sections were made while.the material was fresh. From these data the several organs were projected as shown in the figures. By this method the position of the organs at the time of death was preserved and have been faithfully projected.

CASE 1.-The cadaver is that of a fairly well-built male negro, aged 30. On examination, left-sided pleurisy with a very small effusion, adherent right pleurisy and pericarditis

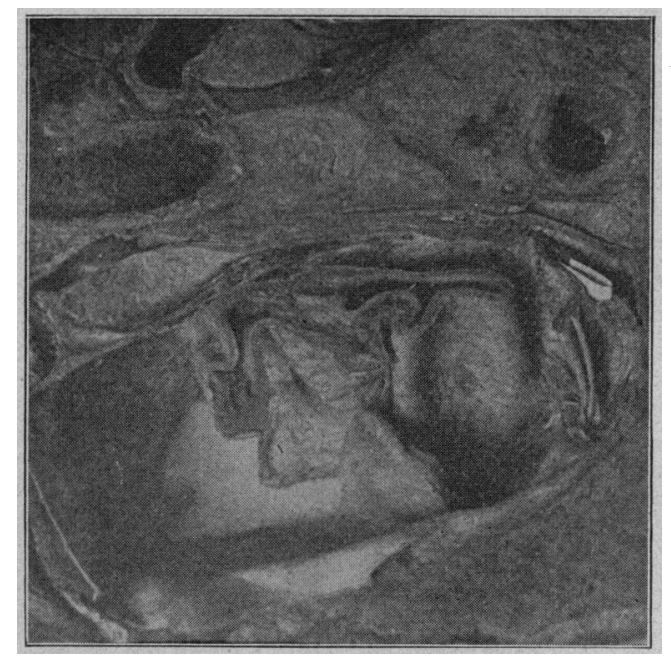

Fig. 3.- Section showing the superior portion of the pericardial sac and the collapsed superior vena cava through which has been passed a piece of paper.

with effusion were observed. In Figure 1 the general relationship of the organs is very well shown. Only those points of immediate interest will be described.

The heart (Figs. 1 and 2) and the superior cava (Fig. 1, d) are both collapsed, and the lumen of the superior cava is $Y$ - shaped (Fig. 1, f) from the point where it enters the pericardium to the right auricle. In Figure 3 is seen a piece of paper that has been passed through the vein from above. 'The superior cava above this constriction was distended with blood.

The inferior cava is collapsed (Fig. 1, i). In Figure 4 a piece of paper has been passed through the vein from below. Below the collapsed portion the vein was distended with blood.

CASE 2.-Cadaver is that of a male negro, aged 29, well formed and fairly well nourished. Examination revealed tuber: culous consolidation, with a small cavity formation in the left lung, and pericarditis with effusion. In amount the effusion was about the same as in Case 1. The relative displacement of organs is also similar to Case 1. The heart, however, and venæ cavæ are greatly distended (Fig. 5).

In the first case the vanæ cavæ within the pericardial sac are collapsed; in the second case, distended. The conditions here are flexible walled tubes (venæ cavæ) passing into and partially through a distended sac, the walls of which are flexible and elastic (pericardium); consequently the degree of distension of the veins must depend on the relationship between the intravenous and intrapericardial pressures. If the venous pressure is greater the veins must be distended; if less, collapsed. But if the pericardial pressure is sufficient to collapse the veins no blood can enter the heart and death must

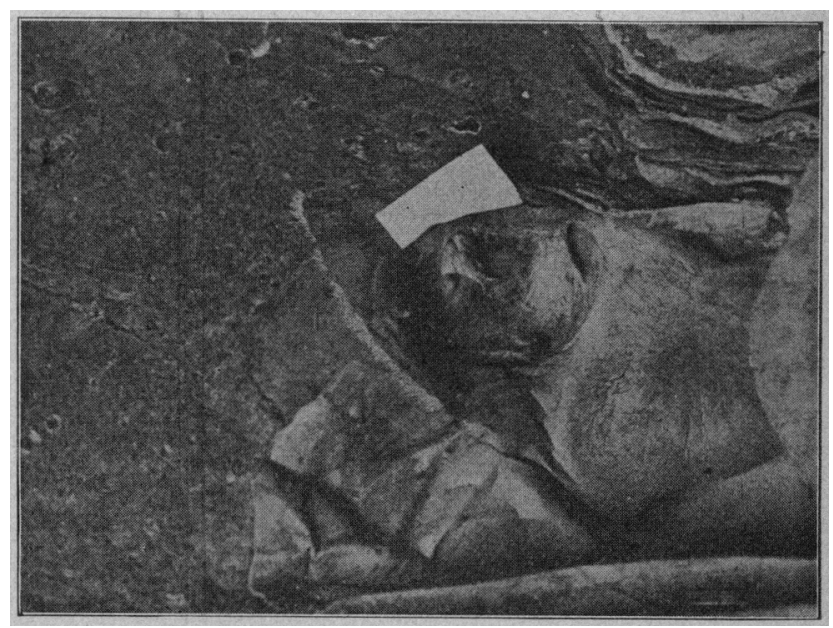

Fig. 4.- Section just above the entrance of the inferior cava into the pericardial sac. A piece of paper has been passed through the collapsed lumen. In front of the paper the depression of the pericardial wall into the distended vein is well shown.

follow. During life, then, the pericardial pressure must remain below that in the veins. If the venous pressure is sufficient to distend the veins a relatively normal amount of blood will flow to the heart.

The pericardial sac is larger than the heart contained therein; consequently a small quantity of fluid may collect in the sac without materially changing the pericardial pressure. But if the fluid continues to collect, the pericardium must be more or less distended and the pericardial pressure positively increased. Owing to the negative, or slightly positive, pressure within the veins a relatively great effect is produced on them by a small increase in the pericardial pressure. This increase in pericardial pressure must, in a proportionate degree, constrict the venæ cavæ (stenosis of venæ cavæ). This constriction must obstruct the flow of blood through the veins, producing a congestion and rise in venous pressure. This rise in venous pressure causes the blood to either dilate the venæ cavæ to the normal or to flow faster through the constricted portion. With each increase in the pericar- 
dial pressure the veins must be further compressed or obstructed, producing additional congestion and rise of venous pressure. 'This process must continue until the limit of venous congestion and pressure is reached.

As the venous pressure changes during inspiration and expiration, there is at all times a maximum and minimum venous pressure. The pericardial pressure must be lower than the minimum pressure or the veins must be closed during the period of lowest pressure. This procedure would cause additional congestion and a rise of venous pressure above that in the pericardium.

The thick, strong pericardial wall, when distended by a pressure almost as great as that within the veins, can not be influenced as casily as the thin walls of the veins by the respiratory change in intra-thoracic pressure. Consequently the pericardial pressure remains during inspiration and expiration more constant than the venous pressure. approach the venous pressure. As it rises it must pass the minimum renous prossure to remain for a time at various points between the maximum and minimum venous pressure.

Whenever the pericardial pressure is greater than that in the veins the latter must be constrieted or collapsed. The degree of constriction must be determined by the difference in pressure. The flow of blood to the right leart must decrease proportionately to the constriction of the veins, as further rise in venous pressure is impossible. The lower venous pressure is during inspiration. Consequently, the greatest constriction of the veins oceurs, and the minimum quantity of blood flows to the heart, during inspiration. During expiration the venous pressure rises above that in the pericardium; the veins are dilated and the maximum quantity of blood flows to the heart. This maximum (expiratory) and minimum (inspiratory) flow of blood to the heart must

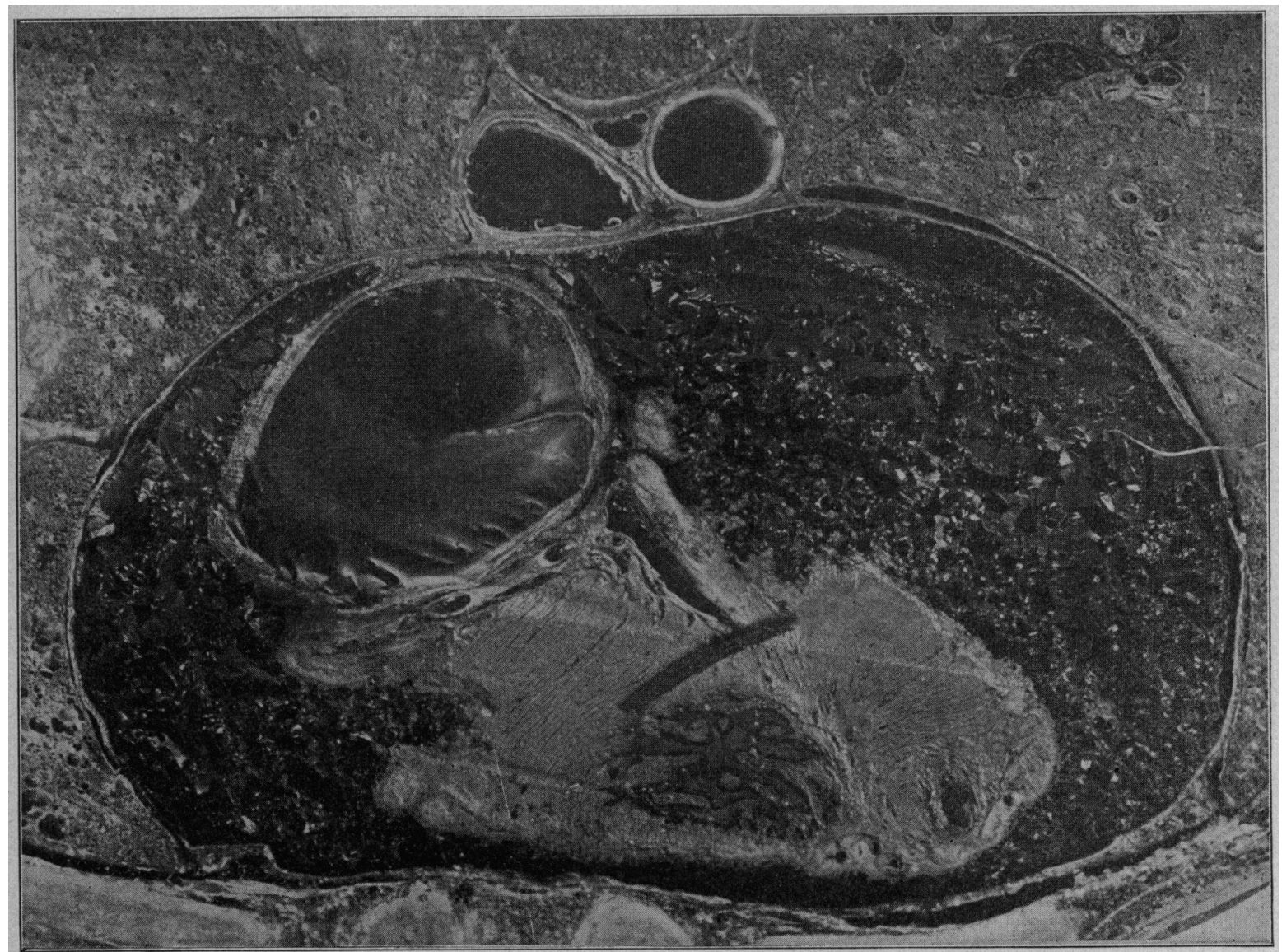

Fig. 5-Section through lower portion of pericardial sac. The coagulated fluid surrounds the lower portion of the heart. To the subject's right is seen the lower portion of the distended right auricle and inferior vena cava.

The venous congestion and rise in pressure become a compensatory congestion and a rise in pressure to compensate the pericardial pressure in exactly the same sense as the left auricle dilates and creates additional pressure to compensate a stenosis in the mitral opening, and as such must be subject, in a measure, to the same laws of reserve forces and broken compensation to which the heart chambers are subjected.

When the limit of venous congestion and pressure has been reached each rise in pericardial pressure is not followed by a rise in venous pressure; the veins begin to fail to compensate the pericardial pressure, and there develops a broken compensation in a compensatory venous congestion. The pericardial pressure may now continue while the pericardial pressure remains between the maximum and minimum venous pressures, or during the stage of broken compensation in the venous congestion.

The amount of blood entering the right heart must determine the condition of the pulmonary circulation, and this in turn determines the condition of the general circulation. The diminished amount of blood during inspiration gives lowered arterial tension-rapid and small pulse. The increased expiratory amount of blood gives a rise in arterial tension-decrease in pulse rate and increase in volume. This is the pulsus paradoxus. As the pericardial pressure approaches the maximum venous pressure the degree of pulsus paradoxus increases. 
Pulsus paradoxus in pericarditis with effusion is cansed by brokell compensation in a compensatory venous congestion. If this is so pulsus paradoxus is a sign of broken compensation in the venous congestion, and denotes the time when the pericardial pressure must be reduced or death may at any time follow-due to constriction of the venæ cavæ beyond the point when sufficient blood to maintain life can enter the right heart.

Pulsus paradoxus should appear relatively early in cases with thick, strong pericardial walls, and relatively late in thin, elastic pericardial walls.

\section{SUMMARY.}

1. Pericardial effusion produces stenosis of the venæ cavæ.

2. This stenosis is relatively compensated by a rise in venous pressure.

3. This compensation fails when the pericardial pressure is greater than the venous pressure.

4. Owing to respiratory change in venous pressure the degree of broken compensation varies in inspiration and expiration-greatest in inspiration, least in expiration.

5 . The variation in compensation carries varying quantities of blood to right heart (and to general circulation) -least in inspiration, greatest in expiration.

6. The respiratory variation in quantity of blood passing to general circulation is sufficient to explain pulsus paradoxus.

Nore.-Since writing the above article Franke ${ }^{2}$ calls attention to venous and hepatic compensation in cases of tricuspid insufficiency, and likens their action to that of the right ventricle in mitral lesions.-W. J. C.

\section{DRAINAGE OF THE HEPATIC DUCT,}

CONSIDERJE IESPECIALIJY IN SERIOUS INFECTIOUS PROCESSES OF THE LIVER.

CHARLES GREENE CUMSTON, M.D. Boston.

In a recent paper ${ }^{1}$ relative to the advantages of surgical treatment of biliary infection resulting in hepatic cirrhosis, I pointed out that the large number of cirrhoses represented the last stage of an irritative process in the liver and were in reality chronic hepatites originating from infection. Biliary cirrhosis is at the present time considered as infectious radicular angiocholitis, either subacute or chronic, and consequently it is quite logical to treat the pathologic condition like any infectious angiocholitis; in other words, by drainage of the gall bladder in order to give exit to the septic bile. In order to obtain a successful outcome, however, the drainage should be instituted at a time when the hepatic cell has not been destroved by a sclerous process resulting from the infection. On the other hand, a new conception has come to light which accords to infection a part in the pathogenesis of vascular cirrhosis; consequently it is logical to foresee that drainage of the gall bladder will be the method of choice, because it seems to very favorably act on the intrabepatic venous circulation. As the title of this paper indicates, the question of drainage of the hepatic duct will be considered particularly from the standpoint of serious infectious processes of the liver. either arising from calculi or other sources. This form of drainage is indicated when there is possibility of bil-

2. Wien. klln. Wochschr., 1906, xix, 956. Extract in Am. Jour Med. Sci., 1907. cxxxiil, 153.

1. Clinical Journal, London, Sept. 19, 1906. iary retention, because it has been amply proven that when there is an obstruction of the principal biliary tracts, retention of bile follows with an increase in size of the liver and dilatation of the hepatic duct, which renders drainage from this canal fairly easy to realize. Drainage of the hepatic duct does not appear any more complicated than other surgical interferences on the biliary tract, and, although in some instances it may be difficult, the excellent results that it has given should encourage surgeons to continue in this direction and to employ it systematically in every case where it is indicated.

As to the technic of drainage of the hepatic duct, there are three principal methods along with a few others which may be considered as possessing special applications. In the first place, we have drainage of the cystic duct and gall bladder. The latter having been opened, a drainage tube is introduced through the dilated cystic duct down to the hepatic duct; in other words, this being complementary to cholecystostomy in general. Secondly, we have drainage by the choledochus after incision of this duct, the drainage tube being pushed down to the hepatic duct. Both of these procedures may be classified under the head of indirect drainage of the hepatic duct as distinguished from the third procedure, which I would call direct drainage of the hepatic duct because the canal is directly incised and a drain introduced into its lumen. As to exceptional methods we have two, namely, transhepatic hepaticostomy, the incision being made directly through the hepatic parenchyma, followed by opening the dilated hepatic duct. The second technic may be termed infrahepatic hepaticostomy. Here the incision of the dilated hepatic duct is made directly into the latter as it projects under the anterior border of the liver. The first three procedures are employed currently according to the given case, while the last two so far have been employed in a restricted number of cases only. Direct drainage of the hepatic duct was, I believe, undertaken the first time by Cabot in 1892 during hepaticostomy for calculi, and I will now endeavor to demonstrate how this duct may be reached, explored and directly drained.

The hepatic duct is deeply seated and hidden by the anterior border of the liver and transverse colon, which usually appear in the abdominal incision. It is not, then, to be wondered at that a number of abdominal incisions have been advised in order to offer the largest operative field so as to facilitate manipulations deep down in the abdominal cavity. One important point must first be considered. I refer to the position given to the pationt on the operating table. A reversed Trendelenburg position was adviced by Elliot in 1894, so that the patient's head would be raised and the pelvis lowered allowing the intestinal mass to gravitate toward the pelvic cavity and thus recede from the region of the liver. Other operators simply have the patient placed horizontally. Mayo-Robson's idea of inserting a hard cushion under the dorso-lumbar region is, I believe, the hest, because it more freely exposes the field of operation and consequently facilitates the surgical maneuvers.

Considering, now, the various incisions which have been proposed, Kehr employs a bayonet-shaped cut (Wellenschnitt), commencing at the xyphoid process and carried vertically down the linea alba and then hroucht oblinuelv to the right, parallel to and two fingers' breadth from the costal border, and then, again becoming vertical, is continued nearly to the middle of 